Article

\title{
Electrochemical Evaluation of Laccase Activity in Must
}

\author{
Szilveszter Gáspár ${ }^{1}\left[\right.$, Elena Brinduse ${ }^{2}$ and Alina Vasilescu ${ }^{1, *(\mathbb{D}}$ \\ 1 International Centre of Biodynamics, 1B Intrarea Portocalelor, 060101 Bucharest, Romania; \\ sgaspar@biodyn.ro \\ 2 Research and Development Institute for Vine and Wine, 2 Valea Mantei, Valea Calugareasca, \\ 107620 Prahova, Romania; elabrinduse@gmail.com \\ * Correspondence: avasilescu@biodyn.ro; Tel.: +40-21-310-4354
}

Received: 1 November 2020; Accepted: 1 December 2020; Published: 7 December 2020

check for updates

\begin{abstract}
As laccase (produced by Botrytis cinerea) can significantly alter the properties of wine, winemakers frequently use commercially available colorimetric kits and spectrophotometers to measure the activity of this enzyme in grapes, must and wine. Although the used kits are based on electrochemically active substrates (such as syringaldazine and 2,2'-azino-bis(3-ethylbenzothiazoline6-sulfonic acid), ABTS), the electrochemical determination of laccase activity as an alternative to the colorimetric determination was not thoroughly investigated up to now. Therefore, in the present work, we explored the electrochemical determination of laccase activity. Laccase activity measurements were carried out using either carbon fiber microelectrodes or screen-printed electrodes as working electrodes, either syringaldazine or ABTS as the electrochemically active laccase substrate, and either cyclic voltammetry or constant potential amperometry as the electrochemical method. The best performing approach, which combines ABTS, screen-printed gold electrodes, and constant potential amperometry, allowed identifying laccase positive must sample (i.e., must samples with $>3 \mathrm{U} / \mathrm{mL}$ laccase) in about $5 \mathrm{~min}$.
\end{abstract}

Keywords: laccase; ABTS; electrochemical sensor; carbon fiber microelectrode; screen-printed electrodes; grapes; must

\section{Introduction}

Laccases (E.C 1.10.3.2) are copper oxidase enzymes produced by fungi, plants, and bacteria that catalyze the oxidation of a variety of phenolic and nonphenolic substrates in the presence of molecular oxygen. Laccase is also one of the metabolites produced in grapes by Botrytis cinerea, a necrotrophic fungus producing significant economic damages in vineyards worldwide. Wines produced from infected grapes suffer enzymatic oxidative processes, irreversibly affecting their organoleptic properties. Detection of Botrytis cinerea in grapes using DNA- or antibody-based methods [1,2] is direct and accurate, but it is also complex, time-consuming, and costly, despite recent progress [3,4]. Alternative indirect methods of detecting Botrytis report on indicators such as laccase, gluconic acid, and glycerol, whose production is triggered in infected grapes [2]. While diagnostic methods based on infrared [2] and Raman spectroscopy [5] are emerging, fast, specific, and cost-effective methods for determining the degree of contamination by Botrytis cinerea are not yet available. In this context, even though it is not a direct and specific indicator, laccase activity is used to detect batches of Botrytis-affected grapes and musts in order to take corrective actions.

The spectrophotometric method developed by Dubourdieu and Grassin is among the widely used methods for determining laccase activity. It is based on syringaldazine (a reagent specific to laccase $[6,7]$ that is not converted by the tyrosinase present in grapes) and is suitable for automated 
measurements [8]. Commercially available semiquantitative colorimetric kits, e.g., the Dolmar laccase activity test [9] and the Laffort Botrytitest kit [10], enable testing in under 15 min without any special equipment. Laccase activity expressed by this syringaldazine-based method serves as a critical threshold for highly affected musts/wine. Despite some variation in the literature regarding this critical value, it is generally considered that red musts with more than $3 \mathrm{U} / \mathrm{mL}$ laccase will suffer oxidative processes, leading to wine browning [6]. For these musts, corrective actions such as treatment with $\mathrm{SO}_{2}$ must be taken at an early stage of wine production.

Laccase is inhibited by phenolic compounds from grapes such as tannins and anthocyanins [3]. Therefore, accurate measurements of laccase activity require the pretreatment of grape musts with poly(vinylpolypyrrolidone) (PVPP) to eliminate the phenolic compounds and reduce interference [7]. Another issue with the colorimetric tests with syringaldazine, which measure the formation of a pink colored compound, involves false results, sometimes reported for insufficiently discolored red wines [11]. Electrochemical methods enable accurate measurements in colored samples. A portable testing device using syringaldazine and electrochemical detection was developed in the European SAFEGRAPE project (2009-2011), yet it is neither described in papers nor commercially available (to the best of our knowledge) [12].

Many other methods for determining laccase activity using various substrates and spectrophotometric or fluorimetric detection or based on the polarographic determination of the oxygen consumed in the enzymatic reaction were described $[13,14]$. ABTS is another preferred substrate for laccase, having the advantage of a good water solubility and of an oxidized form that has a different color than wine's (green-blue), hence a lower risk of false results. While there are several commercial kits based on ABTS, detecting down to $2 \mathrm{mU} / \mathrm{mL}$ laccase (e.g., from MyBioSource, Inc., San Diego, CA, USA [15], BioVision, Inc, Milpitas, CA, USA [16]), they require laboratory-dedicated equipment such as spectrophotometers or plate readers, and thus they are not appropriate for in-field measurements.

Electrochemical approaches are cost-effective, amenable to miniaturization and in-field testing and were successfully used to determine the activity of several enzymes such as $\beta$-lactamase [17,18], cholinesterase [19], protein kinase [20], sphingomyelinase [21] and alkaline phosphatase [22], among others. Additionally, many laccase substrates, including syringaldazine and ABTS, are electrochemically active [23].

Several electrochemical sensors were reported using ABTS for the determination of antioxidant capacity of wines $[24,25]$ or the laccase/ABTS system as a mediator for the oxidation of other substrates (e.g., lignin [26]), yet the electrochemical determination of laccase activity based on ABTS was rarely investigated [27]. Thus, with the goal to develop a fast and sensitive method adaptable to the in-field screening of Botrytis cinerea-affected grapes, we investigated the determination of laccase activity based on the use of ABTS in solution and the electrochemical detection of the enzymatic product ABTS.+.

Aiming at high sensitivity, we investigated the detection of ABTS ${ }^{+}$via cyclic voltammetry using carbon fiber microelectrodes (CFMEs). Additionally, we used screen-printed gold electrodes (SPAuEs) and constant potential amperometry as a simple and accessible way for measuring the activity of laccase in must. Tests with musts obtained from Botrytis cinerea-contaminated grapes were compared to parallel analysis by the reference spectrophotometric method with syringaldazine. Analytical challenges are discussed.

\section{Materials and Methods}

\subsection{Reagents}

The sodium acetate, glacial acetic acid, sodium phosphate (monobasic and dibasic), syringaldazine, laccase from Trametes versicolor and polyvinylpolypyrrolidone (PVPP) were purchased from Sigma Aldrich (now Merck, Germany), and the 2,2'-azino-bis(3-ethylbenzothiazoline-6-sulfonic acid) (ABTS) was purchased from Roche Diagnostics (Rotkreuz, Switzerland). Centrifuge filters with $10 \mathrm{kDa}$ cutoff were supplied from Corning, Loughborough, England. 
Buffer solutions used in this work were $0.1 \mathrm{M}$ acetate $(\mathrm{pH} 4,4.5,5$ and 5.5) and a phosphate buffer $0.1 \mathrm{M} \mathrm{pH}$ 6. All solutions were prepared using water from a Direct-Q 3 UV water purification system from Millipore SAS (Molsheim, France).

\subsection{Measurements of Laccase Activity Using Electrochemistry}

Both screen-printed electrodes and CFMEs were used to measure laccase activity through electrochemistry. The screen-printed Au electrodes (DRP 220 AT) were from Metrohm Dropsens (Oviedo, Spain). These are three-electrode systems printed on a ceramic support, including a $4 \mathrm{~mm}$ diameter Au working electrode, Au counter electrode and Ag reference electrode. The CFMEs were built using carbon microfibers with a diameter of $37 \mu \mathrm{m}$ as previously described by us [28].

Electrochemistry experiments were performed using a VSP potentiostat and a computer equipped with the EC Lab software (BioLogic SAS, Grenoble, France). CFMEs were completed with a Pt wire counter electrode and a $\mathrm{Ag} / \mathrm{AgCl}$ wire pseudoreference electrode when used in cyclic voltammetry. For laccase activity measurements, this three-electrode system was immersed into a 4 mL electrochemical cell containing $2.3 \mathrm{~mL}$ ABTS solution in $0.1 \mathrm{M}$ acetate buffer at $\mathrm{pH} 4.5$. Cyclic voltammograms were next recorded until the oxidation and reduction of ABTS produced stable currents. Then, either laccase standard solution $(68.6 \mathrm{U} / \mathrm{mL})$ or $150 \mu \mathrm{L}$ of must sample was injected into the electrochemical cell and additional voltammograms were recorded to observe the evolution of the oxidation and reduction currents given by ABTS. The evolution of these currents was found to be laccase-activity-dependent for both standard solutions and must samples.

Chronoamperometry experiments using the screen-printed electrodes were performed, with the electrodes fixed horizontally, by applying onto the electrode surface a total volume of $100 \mu \mathrm{L}$ solution (25 $\mu \mathrm{L}$ sample and $75 \mu \mathrm{L}$ ABTS solution, $0.4 \mathrm{mM}$ in $0.1 \mathrm{M}$ acetate buffer $\mathrm{pH} 4.5$ ) and polarizing the working electrode at $0 \mathrm{~V}$ versus the screen-printed reference electrode. The current intensity was recorded for $300 \mathrm{~s}$ and the difference between the current intensity at $30 \mathrm{~s}$ and at $300 \mathrm{~s}$ was taken as the analytical signal to be correlated with laccase activity in the sample.

\subsection{Measurement of Laccase Activity Using Spectrophotometry}

Measurements of laccase activity were performed using an Evolution 600 spectrophotometer (from Thermo Scientific, Gloucester, UK), at the fixed wavelength of $530 \mathrm{~nm}$.

The method of Grassin and Dubourdieu [6] was followed, using syringaldazine as enzyme substrate and monitoring the enzymatic reaction at $530 \mathrm{~nm}$, where the extinction coefficient of oxidized syringaldazine is $65,000 \mathrm{M}^{-1} \mathrm{~cm}^{-1}$. According to the method, one unit of enzymatic activity is defined as the amount of enzyme catalyzing the oxidation of a nanomole of syringaldazine per minute in the reaction conditions.

\subsection{Preparation of Grape Musts}

Musts were either provided by the Research and Development Institute for Vine and Wine Valea Calugareasca, Romania (from Sauvignon grapes contaminated with Botrytis cinerea) or were prepared in the laboratory from white or black grapes purchased from a local supermarket. Spiking with laccase was performed by adding an appropriate volume of stock laccase solution into Eppendorf tubes containing white or red must. The unspiked or spiked must samples were filtered through a PVPP cartridge, according to the method of Grassin and Dubourdieu [6] with some modifications: a $1 \mathrm{~mL}$ syringe filter was filled with $0.15 \mathrm{~g}$ of PVPP and a volume of $1 \mathrm{~mL}$ of must was passed through this filter. In some cases, as described in the text, a second filtration was performed by passing the PVPP filtered must through a centrifuge filter with a $10 \mathrm{kDa}$ cutoff. 


\section{Results}

\subsection{Electrochemical Evaluation of Laccase Activity Using CFMEs}

Electrodes are relatively easy to miniaturize; this fact is considered an important advantage of electrochemical analytical methods as compared to optical analytical methods. Electrodes have already been miniaturized, even to sizes facilitating experiments in the tiny intracellular space of a single living cell (see, for example, [29]). Therefore, with laccase activity measurements in a single grape berry in mind, we investigated if CFMEs are suitable for the electrochemical evaluation of laccase activity.

Both syringaldazine and ABTS were initially considered to carry out the present study. However, syringaldazine was observed to show an increased tendency to irreversibly adsorb onto CFMEs. Therefore, in our first experiments, we combined CFMEs with ABTS.

In cyclic voltammetry experiments performed with carbon electrodes in acetate buffer $\mathrm{pH} 5, \mathrm{ABTS}$ displayed two redox couples with formal potentials at $0.469 \mathrm{~V}$ and $0.870 \mathrm{~V}$ [30], corresponding to the following one electron, quasireversible transformations:

$$
\begin{gathered}
\text { ABTS }-e^{-} \rightleftarrows \text { ABTS }^{+} \\
\text {ABTS }^{+}-e^{-}
\end{gathered}
$$

Enzymatic oxidation of ABTS by laccase produces only ABTS.+ [30]; hence, in our cyclic voltammetry experiments, we concentrated on the first redox couple of ABTS, corresponding to the transformation (1), and investigated potential ranges up to $0.7 \mathrm{~V}$.

Figure 1A,B show typical cyclic voltammograms recorded with CFMEs in the presence of $0.5 \mathrm{mM}$ of ABTS and two different concentrations of laccase $(0.12 \mathrm{U} / \mathrm{mL}$ and $0.47 \mathrm{U} / \mathrm{mL})$. As one can observe, the electrochemical oxidation of ABTS gives S-shaped voltammograms due to the enhanced, hemispherical diffusion of ABTS to the surface of the microelectrodes. Notably, in the absence of laccase, these voltammograms are stable for extended periods of time (>30 min) presenting no signs of ABTS adsorption to the surface of the microelectrode (see red signals in Figure $1 \mathrm{~A}, \mathrm{~B}$ ). However, in the presence of laccase, the currents resulting from the oxidation of reduced ABTS (e.g., at $+0.4 \mathrm{~V}$ ) start decreasing over time (see Figure 1C), whereas the currents resulting from the reduction of oxidized ABTS (e.g., at $0 \mathrm{~V}$ ) start increasing over time (see Figure 1D). This time evolution of the voltammograms is due to the laccase consuming reduced ABTS and producing oxidized ABTS, and thus interfering with the electrochemistry of ABTS. Moreover, the decrease of the oxidation currents and the increase of the reduction currents are both faster when the laccase concentration is larger (Figure 1C,D). Cyclic voltammograms similar to those shown in Figure $1 \mathrm{~A}, \mathrm{~B}$ were recorded in the presence of several other concentrations of laccase (from $1.5 \mu \mathrm{g} / \mathrm{mL}$ to $24 \mu \mathrm{g} / \mathrm{mL}$, i.e., from $0.12 \mathrm{U} / \mathrm{mL}$ to $1.89 \mathrm{U} / \mathrm{mL}$ ). The way the oxidation current decreases at $+0.4 \mathrm{~V}$ and the reduction current increases at $0 \mathrm{~V}$ in these voltammograms was then quantified and used to build calibration curves for the determination of laccase activity. The procedure was carried out both at $\mathrm{pH} 6$ (in phosphate buffer) and at pH 4.5 (in acetate buffer). The obtained average calibration curves (see Figure 2) show that laccase converts ABTS about seven times faster at $\mathrm{pH} 4.5$ than at $\mathrm{pH} 6$.

After we obtained the calibration curves shown in Figure 2, we proceeded to analyze must samples spiked with different concentrations of laccase. These must samples (white and red) were obtained from healthy grapes and were tested by the spectrophotometric method with syringaldazine. As expected, no laccase activity was detected. The musts were then spiked with laccase from Trametes versicolor and pretreated with PVPP cartridges as described in the Materials and Methods section. The results obtained from analyzing the must samples are summarized in Table 1. 
A

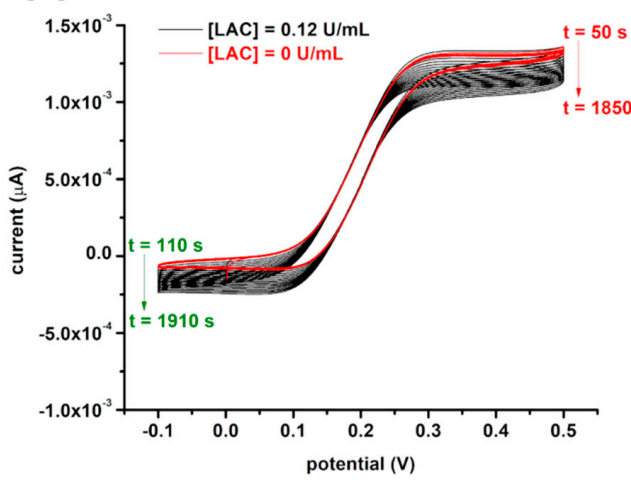

C

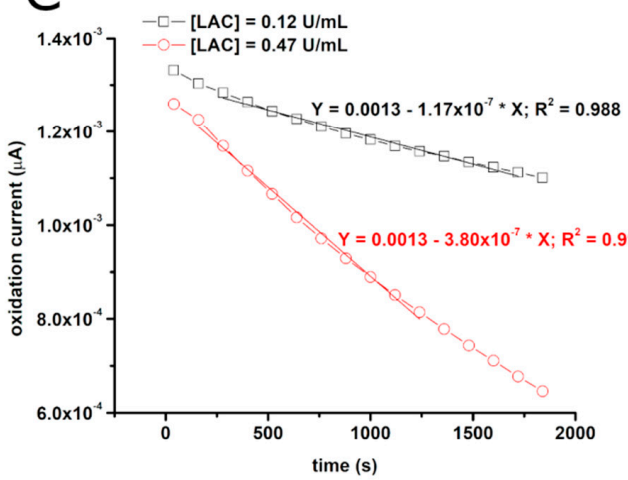

$B$

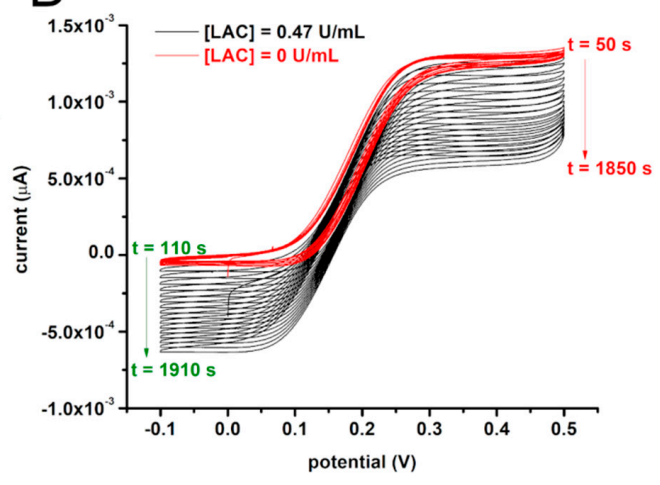

D

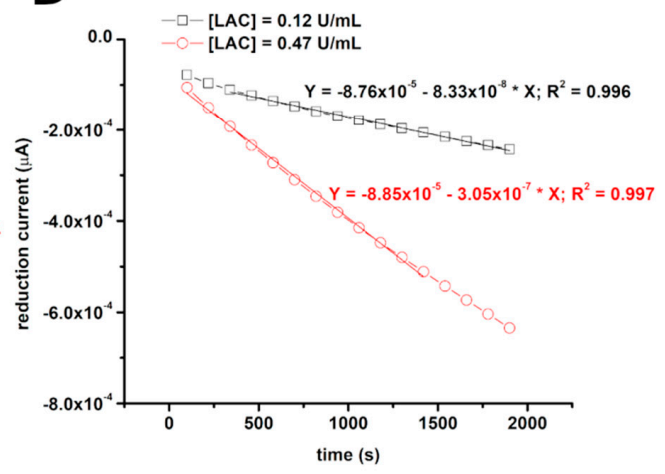

Figure 1. Cyclic voltammograms recorded at a potential scan rate of $10 \mathrm{mV} / \mathrm{s}$ in solutions with $0.5 \mathrm{mM}$ 2,2'-azino-bis(3-ethylbenzothiazoline-6-sulfonic acid) (ABTS) and with two different concentrations of laccase $([\mathrm{LAC}])(\mathbf{A}, \mathbf{B})$, and the time evolution of the current in these voltammograms at $+0.4 \mathrm{~V}$ (where the current is proportional with the concentration of reduced ABTS) and at $0 \mathrm{~V}$ (where the current is proportional with the concentration of oxidized ABTS) (C,D). It is important to note that a negative slope corresponds to current decreases in $\mathrm{C}$ and $\mathrm{D}$ (as reduction currents are considered negative).
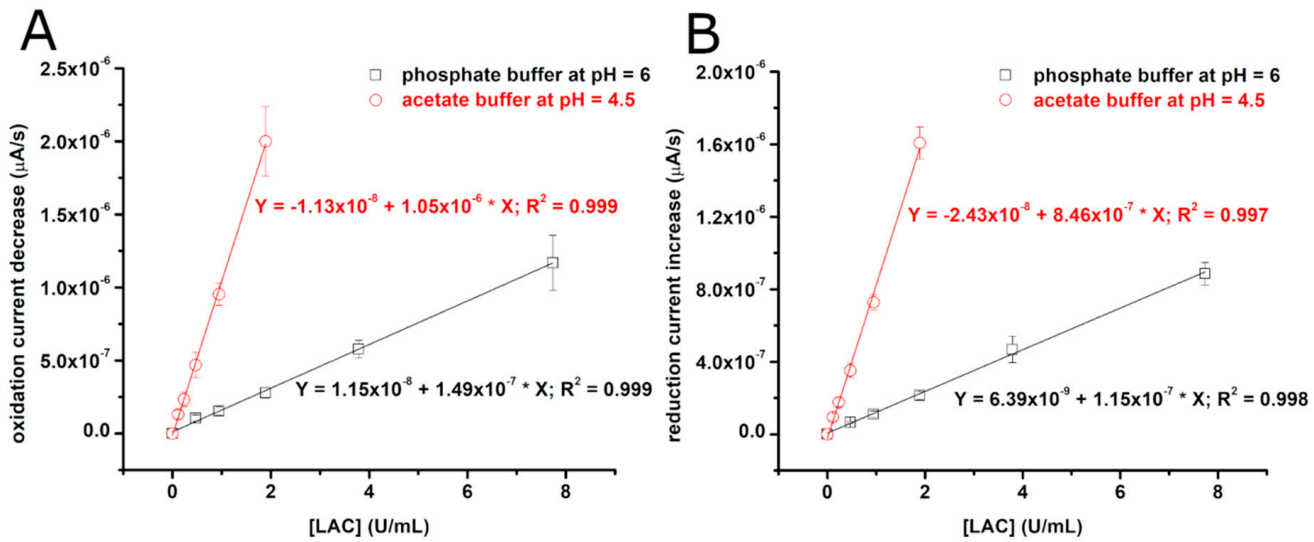

Figure 2. Average calibration curves for the determination of laccase activity. The curves were obtained with three different CFMEs in two different buffers using cyclic voltammetry currents at either $+0.4 \mathrm{~V}$ (where the current is proportional with the concentration of reduced ABTS) (A) or $0 \mathrm{~V}$ (where the current is proportional with the concentration of oxidized ABTS) (B). The ABTS concentration was always $0.5 \mathrm{mM}$. It is important to note that currents at $+0.4 \mathrm{~V}$ decrease when laccase is present, whereas currents at $0 \mathrm{~V}$ increase when laccase is present. 
Table 1. Results of evaluating the laccase content of must samples spiked with known concentrations of laccase. The laccase activity was determined using both oxidation currents (at $+0.4 \mathrm{~V}$ ) and reduction currents (at $0 \mathrm{~V})$.

\begin{tabular}{|c|c|c|c|c|c|c|}
\hline \multirow{2}{*}{ Sample No. } & \multirow{2}{*}{ Must Type } & \multirow{2}{*}{$\begin{array}{l}\text { Spiked Laccase } \\
\quad(\mathrm{u} / \mathrm{mL})\end{array}$} & \multicolumn{2}{|c|}{$\begin{array}{l}\text { Recovered Laccase, Based on } \\
\text { Oxidation Currents }\end{array}$} & \multicolumn{2}{|c|}{$\begin{array}{l}\text { Recovered Laccase, Based on } \\
\text { Reduction Currents }\end{array}$} \\
\hline & & & $\begin{array}{l}\text { Found Laccase } \\
(\mathrm{U} / \mathrm{mL})\end{array}$ & Recovery (\%) & $\begin{array}{c}\text { Found Laccase } \\
(\mathrm{U} / \mathrm{mL})\end{array}$ & Recovery (\%) \\
\hline 1 & \multirow{4}{*}{ Red } & 2.6 & 2.21 & 85 & 2.05 & 78.8 \\
\hline 2 & & 5.2 & 3.77 & 72.5 & 3.54 & 68.1 \\
\hline 3 & & 2.6 & 1.70 & 65.4 & 1.87 & 71.9 \\
\hline 4 & & 2.6 & 1.73 & 66.5 & 1.83 & 70.4 \\
\hline 5 & \multirow{5}{*}{ White } & 2.6 & 2.02 & 77.7 & 2.3 & 88.5 \\
\hline 6 & & 2.6 & 2.72 & 104.6 & 2.63 & 101.2 \\
\hline 7 & & 2.6 & 2.55 & 98.1 & 2.54 & 97.7 \\
\hline 8 & & 5.2 & 4.65 & 89.4 & 4.28 & 82.3 \\
\hline 9 & & 5.2 & 4.86 & 93.5 & 4.09 & 78.7 \\
\hline
\end{tabular}

As one can observe, the CFME-based electrochemical approach has a significant tendency to underestimate the laccase content of must (somewhat more when the must is red as compared to when the must is white). Phenolic compounds that were not removed during sample pretreatment and that are converted by laccase but not detected electrochemically could be the cause of this underestimation. Nevertheless, we consider the possibility offered by the electrochemical method to determine laccase activity at two different potentials interesting and promising as it can provide robustness and reliability. At this point of time, laccase activity determination at positive potentials (e.g., $+0.4 \mathrm{~V}$ ) seems to function in a manner similar to that of laccase activity determination at negative potentials (e.g., $0 \mathrm{~V}$ ). It was also investigated if replacing cyclic voltammetry with constant potential amperometry improves the CFME-based laccase activity assay. Typical current signals recorded in the presence of different laccase concentrations and the average calibration curve for laccase activity determination using amperometry are shown in the Supplementary Material. Unfortunately, when tested with must samples spiked with laccase, the amperometry-based approach showed the same tendency to underestimate the laccase content of must as the cyclic-voltammetry-based approach.

\subsection{Evaluation of Laccase Activity Using SPAuEs}

While the approach based on cyclic voltammetry and CFMEs can sensitively detect laccase and is amenable to further miniaturization, it requires additional development to convert it into a fast, simple and reliable assessment of laccase activity outside the laboratory. Screen-printed systems are commercially available as ready-to-use three-electrode systems, appropriate for analyzing small volume samples. A variety of electrode materials and modifiers are currently available. Constant potential amperometry is an electrochemical method that is available even on the simplest electrochemical equipment. Moreover, it is minimally affected by capacitive currents, has excellent temporal resolution and allows an easier calculation of the laccase activity than potentiodynamic methods. With this in mind, we examined the performances of screen-printed electrodes for the assessment of laccase activity by chronoamperometry.

Initial screening of carbon and gold electrodes emphasized unwanted adsorption of must components on the carbon surface for low sample dilution factors. Consequently, the studies reported below were conducted exclusively using SPAuEs. The measurement principle for laccase activity using SPAuEs, ABTS as substrate and chronoamperometric detection is illustrated in Figure 3. 


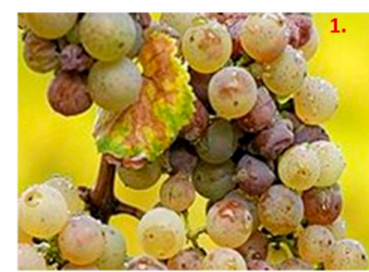

Botrytis cinerea infected grapes

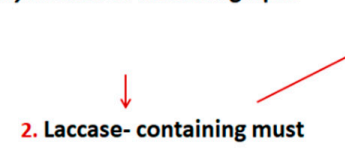



4.

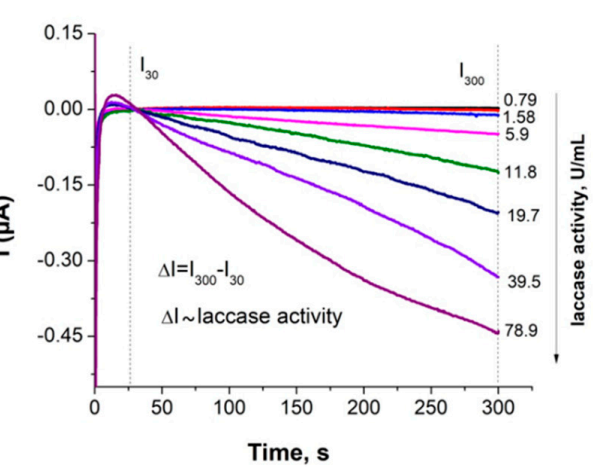

Figure 3. Principle of measuring the activity of laccase in must with SPAuEs: laccase-containing must obtained from Botrytis cinerea-infected grapes is filtered through a PVPP cartridge to eliminate phenolic compounds; then, it is mixed with ABTS on the surface of a SPAuE. The oxidized ABTS formed in the laccase-catalyzed reaction (i.e., $\mathrm{ABTS}^{+}{ }^{+}$) is reduced on the electrode at $0 \mathrm{~V} \mathrm{vs.} \mathrm{Ag} / \mathrm{AgCl}$ and the difference in the cathodic current recorded at $300 \mathrm{~s}$ and $30 \mathrm{~s}(\Delta \mathrm{I})$ is proportional to laccase activity in the must.

\subsubsection{Optimization of The Experimental Conditions and Calibration}

First, the feasibility of exploiting the electrochemistry of ABTS at the surface of SPAuE for measuring laccase activity was confirmed by cyclic voltammetry (reported in the Supplementary Material, Figure S2). Next, the main experimental parameters, i.e., the $\mathrm{pH}$ of the buffer solution, the concentration of ABTS and the value of the applied potential were optimized (Figure $4 \mathrm{~A}-\mathrm{C}$ ). The influence of the applied potential in the chronoamperometric determination of laccase activity was studied in the range from -0.2 to $+0.5 \mathrm{~V}$, using a solution of $7.89 \mathrm{U} / \mathrm{mL}$ laccase from Trametes versicolor and a concentration of ABTS of $0.2 \mathrm{mM}$ in $0.1 \mathrm{M}$ acetate buffer $\mathrm{pH}$. These studies indicated that the largest increase in the cathodic current due to the reduction of the enzymatically generated ABTS.+ ${ }^{+}$was recorded at potentials from 0.050 to $-0.1 \mathrm{~V}$ (see Figure 4A). Additional studies were performed with PVPP-filtered must to identify any potential interferences due to electrochemically active compounds from the grapes. Based on the combined results of these studies, an applied potential of $0 \mathrm{~V}$ was found as optimum. Tests performed with laccase from Trametes versicolor and with a must from Botrytis cinerea-contaminated grapes in acetate buffer with $\mathrm{pH}$ in the range 4.5-6 let us identify an optimum $\mathrm{pH}$ of 4.5 (see Figure 4B). By repeated testing using ABTS concentrations of $0.2,0.4,0.97$ and $1.94 \mathrm{mM}$, the optimum concentration of enzyme substrate was found to be $0.4 \mathrm{mM}$ (see Figure $4 \mathrm{C}$ ).

Calibration experiments with the SPAuE in optimized conditions (i.e., $0.1 \mathrm{M}$ acetate buffer $\mathrm{pH} 4.5$, $0 \mathrm{~V}$ applied potential, $0.4 \mathrm{mM}$ ABTS) led to determining the linear range as $0.79-15.8 \mathrm{U} / \mathrm{mL}$ and the detection limit as $0.5 \mathrm{U} / \mathrm{mL}$, calculated as three times the standard deviation of the blank, divided by the slope of the linear range of the calibration curve. An average sensitivity of $9.23 \pm 1.06 \mathrm{nA} . \mathrm{mL} / \mathrm{U}$ was also calculated, based on $n=6$ calibration curves obtained with different sensors, on different days. A typical calibration curve is shown in Figure 4D.

\subsubsection{Investigation of The Grape Must Matrix Effects}

Phenolic antioxidants in grapes/must/wine can affect the determination of laccase activity in different ways: (i) by reacting with ABTS ${ }^{+}$, i.e., by scavenging the stable radical cation ABTS ${ }^{+}$; (ii) by acting as substrates for laccases; (iii) by presenting electrochemical activity in the potential range used with the proposed sensor. Therefore, an accurate determination of laccase activity requires elimination of possibly interfering phenolic compounds prior to analysis. This was achieved by filtering the grape must through a PVPP cartridge according to the procedure proposed by Dubourdieu [7] adapted for small sample volumes. The electrochemical activity and potential interferences of the PVPP-filtered 
must were checked by chronoamperometry at $0 \mathrm{~V}$ (Figure 5A). With PVPP-filtered red must, a small anodic current was observed (red colored signal in Figure 5A), as compared to the stable signal in buffer (black colored signal in Figure 5A) and to the cathodic current, growing with time in laccase-containing solutions (blue colored signal in Figure 5A). Consequently, there are no electrochemical reduction processes in PVPP-filtered must that interfere with the reduction of the enzymatically formed ABTS ${ }^{+}$.

A
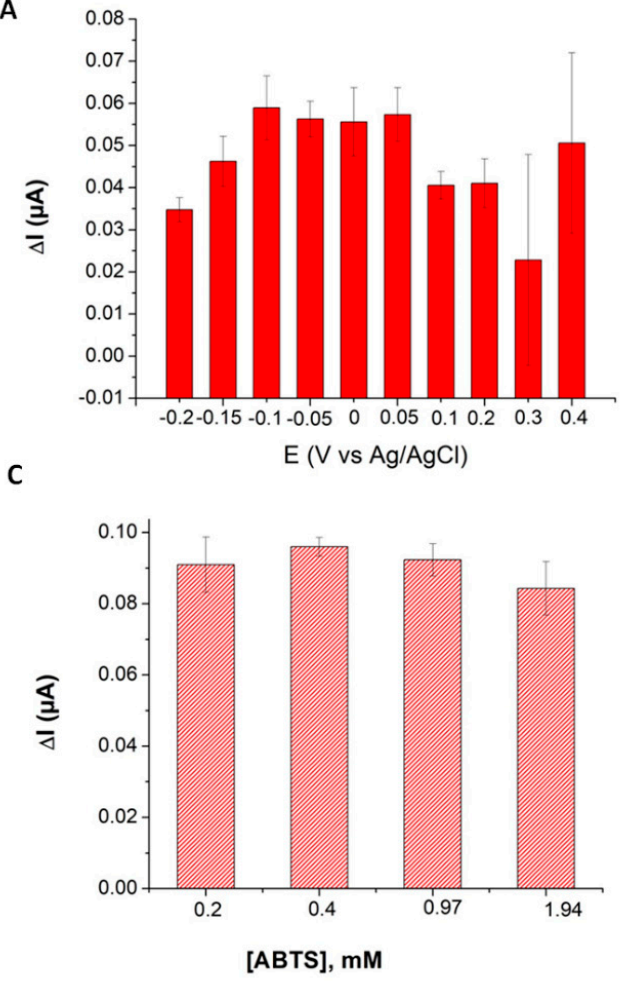
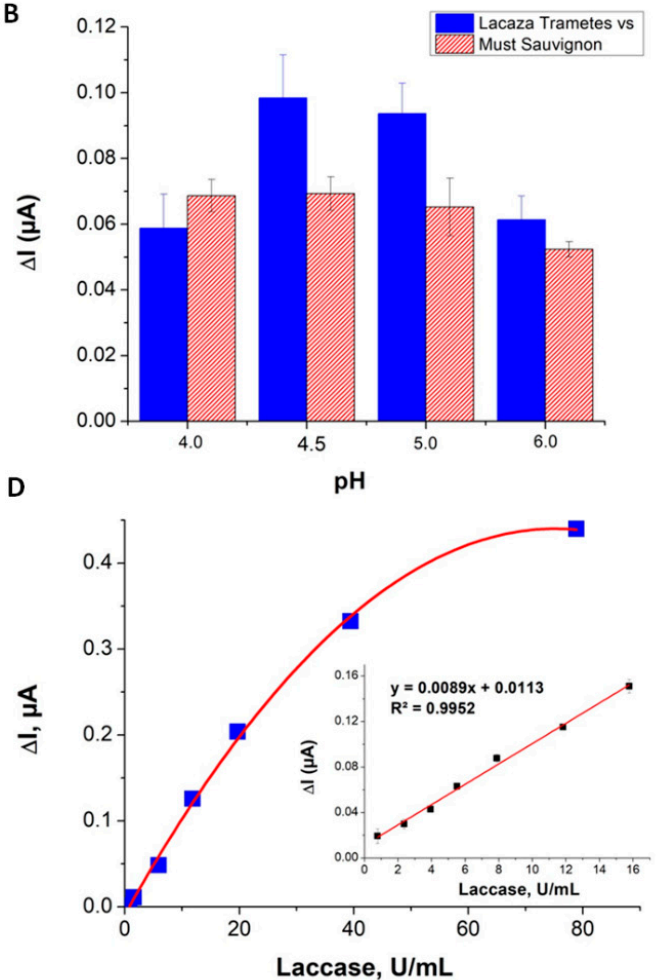

Figure 4. Optimization of the experimental parameters for the electrochemical assay of laccase using SPAuEs: (A) applied potential, (B) $\mathrm{pH},(\mathbf{C})$ concentration of ABTS. (D) Typical calibration curve for the determination of laccase activity, showing in the inset the linear range of the method.

These promising initial results were reconfirmed by performing calibration experiments with the same sensor, for (i) a series of five laccase standard solutions made in buffer with laccase concentrations in the range from 0.79 to $15.8 \mathrm{U} / \mathrm{mL}$ and for (ii) white and (iii) red must spiked with laccase in the same concentrations. A total of $n=3$ replicate assays were performed at each concentration.

As illustrated in Figure 5B, the sensitivity of the electrochemical detection of laccase activity is significantly lower in must than in buffer, and the matrix effect is more evident for red musts compared to the white musts. Most probably, the consistently lower laccase activity in red musts is due to the phenolic compounds (more abundant in red musts compared to white musts), which are either outcompeting ABTS for oxidation by laccase or quenching the ABTS ${ }^{+}$formed in the enzymatic reaction. The outcome of both processes is a smaller amount of oxidized ABTS available for electrochemical reduction on the electrode.

Further investigation of possible interferences focused on comparing the results of the electrochemical assay using SPAuE and ABTS with the spectrophotometric method using syringaldazine as enzyme substrate. In these experiments, a series of grape must samples with activities in the range 2.4-15.8 U/mL was analyzed, including both Botrytis cinerea-contaminated samples and must from healthy grapes intentionally spiked with laccase from Trametes versicolor. The results in Figure 5C emphasize a relatively good agreement between the results obtained by the two methods, better for white musts than for the red ones, i.e., the correlation coefficient $R^{2}$ decreases from 0.9072 to 0.8475 when red wines are included in the comparison. From the results in Figure 5C, it is obvious that the laccase activity of red musts (shown in red) is underestimated by the electrochemical method compared to 
the spectrophotometric method with syringaldazine. In contrast, in some white musts, we observed significantly higher activities measured electrochemically with ABTS than by the spectrophotometric method. Both syringaldazine and ABTS are used as enzyme substrates for measuring the laccase activity of musts by optical methods, as detailed in the Introduction. While syringaldazine is considered specific for laccase, it has some disadvantages related to the low solubility in aqueous solutions, low stability, adsorption on carbon surface and color similar to that of wine. Instead, ABTS is considered by some reports a better alternative for optical detection [11]. More relevant for this work, the experimental conditions for the spectrophotometric test with syringaldazine ( $\mathrm{pH} 5.5$, presence of ethanol in the reaction medium) and for the proposed electrochemical assay using ABTS ( $\mathrm{pH} 4.5$, no organic solvent) are quite different. To verify if the differences reported in Figure 5 are due to the electrochemical method or are mainly associated with the different substrate and experimental conditions, we performed parallel measurements using the proposed electrochemical method and using a colorimetric test with ABTS for a set of 14 samples including both white and red musts. The tests were performed in the same experimental conditions ( $\mathrm{pH}$, concentration of ABTS). The results reported in Supplementary Material, Figure S3A,B show good agreement between activities measured via chronoamperometry and values determined spectrophotometrically for all wines.

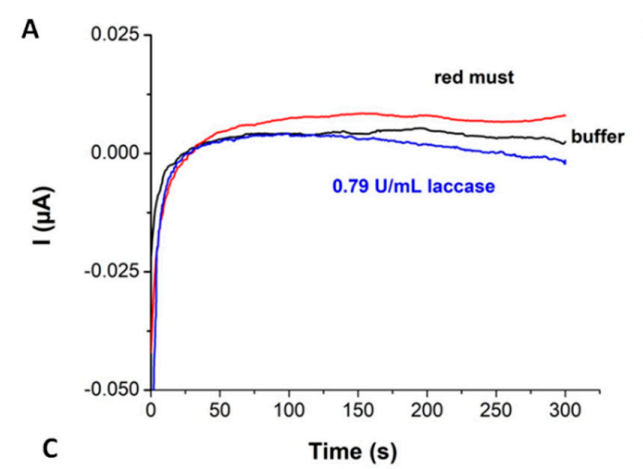

B
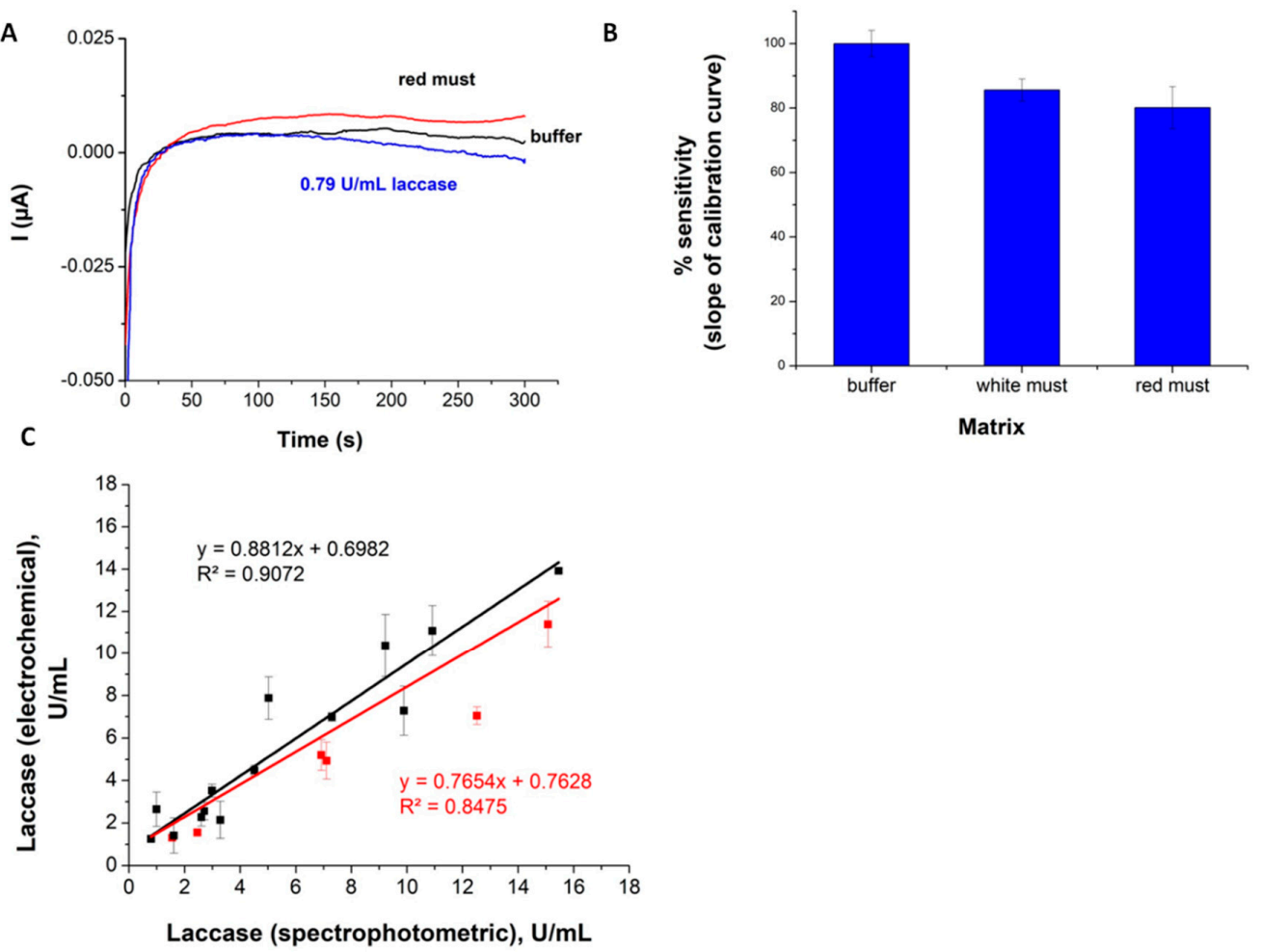

Figure 5. (A) Chronoamperometric signals recorded with SPAuEs at $0 \mathrm{~V}$, in $0.4 \mathrm{mM}$ ABTS solutions made in $0.1 \mathrm{M}$ acetate buffer $\mathrm{pH} 5$ (black), PVPP-filtered red must (red) and $0.79 \mathrm{U} / \mathrm{mL}$ laccase solution (blue). (B) Sensitivity of the electrochemical assay (slope of the calibration curve) in buffer, white and red must, respectively. (C) Comparison between the laccase activity measurements performed by the spectrophotometric method based on syringaldazine and by the proposed electrochemical method based on ABTS and SPAuEs. Black: white musts from Botrytis cinerea-contaminated grapes and from white grapes spiked with laccase. Red: red musts spiked with laccase. The linear fit between the two methods for all samples (white and red musts included) is shown in red; the fit for white-only musts is shown in black.

Consequently, the differences observed between the reference spectrophotometric method with syringaldazine and the proposed electrochemical assay are mostly due to the differences in catalytic oxidation of the two substrates, syringaldazine and ABTS by laccase [23], and to the different ways 
in which these catalytic processes are affected by grape phenolics. Electroactive phenolic compounds or phenols reacting with ABTS in a laccase-mediated reaction are possible sources of interference in the proposed electrochemical assay. However, analysis of laccase-free musts in the presence of ABTS by chronoamperometry at $0 \mathrm{~V}$ did not show any interference by a direct contribution to the cathodic current (Figure 5A).

Optimization of sample preparation is anticipated to eliminate the inaccuracies due to interfering compounds in musts. As a preliminary solution, we investigated the introduction of a second filtration step through a centrifuge filter with a cutoff of $10 \mathrm{KDa}$, after the filtration through the PVPP cartridge. This procedure should eliminate all small molecular weight compounds such as phenolic compounds. A first test was conducted using a white must for which the difference between the result given by the spectrophotometric method and the result given by the electrochemical assay was large, i.e., no laccase was detected in the PVPP-filtered must using spectrophotometry, while $2.41 \pm 0.23 \mathrm{U} / \mathrm{mL}$ laccase was measured using the electrochemical method. When the additional filtration through the $10 \mathrm{kDa}$ filter was performed, the activity determined using spectrophotometry was $2.71 \pm 0.15 \mathrm{U} / \mathrm{mL}$, in good agreement with the results from the electrochemical method, $2.56 \pm 0.42 \mathrm{U} / \mathrm{mL}$. While the results remain to be confirmed for more must samples, they suggest that additional filtration would improve the accuracy of measurements using both spectrophotometric and electrochemical methods.

\subsubsection{Accuracy of The Assay}

The accuracy of the electrochemical assay was checked with a series of spiked white and red musts samples with laccase activities covering the linear range of the assay (Table 2). The samples $(1.5 \mathrm{~mL})$ were filtered through the PVPP cartridge, recovering the first $1 \mathrm{~mL}$. While the recovery factors were $88.2 \%-113.4 \%$ in white musts, in red musts the recoveries averaged $73.5 \%$, confirming the matrix effect (observed also with CFMEs, see Table 1).

Table 2. Measurements of laccase activity in grape must with the electrochemical sensor with ABTS and using the spectrophotometric method with syringaldazine.

\begin{tabular}{|c|c|c|c|c|c|}
\hline \multirow[b]{2}{*}{ Must Type } & \multirow{2}{*}{$\begin{array}{c}\text { Spiked } \\
\text { Laccase, } \mathrm{u} / \mathrm{mL}\end{array}$} & \multicolumn{2}{|c|}{ Spectrophotometric Method } & \multicolumn{2}{|c|}{ Electrochemical Sensor } \\
\hline & & $\begin{array}{c}\text { Laccase } \\
\text { Activity, U/mL }\end{array}$ & Recovery (\%) & $\begin{array}{c}\text { Laccase } \\
\text { Activity, U/mL }\end{array}$ & Recovery (\%) \\
\hline \multirow{4}{*}{ White } & 3.95 & $4.51 \pm 0.11$ & $114.4 \pm 2.8$ & $4.47 \pm 0.24$ & $113.4 \pm 6.0$ \\
\hline & 7.89 & $7.30 \pm 0.24$ & $92.5 \pm 3.0$ & $6.99 \pm 0.21$ & $88.6 \pm 2.7$ \\
\hline & 11.8 & $10.91 \pm 0.09$ & $92.2 \pm 0.7$ & $11.09 \pm 1.19$ & $93.7 \pm 10.1$ \\
\hline & 15.8 & $15.5 \pm 1.7$ & $98.0 \pm 11.0$ & $13.9 \pm 0.10$ & $88.3 \pm 0.7$ \\
\hline \multirow{5}{*}{ Red } & 2.37 & $2.45 \pm 0.07$ & $103.7 \pm 3.0$ & $1.56 \pm 0.10$ & $66.0 \pm 4.3$ \\
\hline & 5.52 & $7.11 \pm 0.14$ & $128.7 \pm 2.6$ & $4.93 \pm 0.87$ & $89.3 \pm 15.7$ \\
\hline & 7.89 & $6.92 \pm 0.36$ & $87.7 \pm 4.5$ & $5.20 \pm 0.72$ & $65.9 \pm 9.2$ \\
\hline & 9.47 & $12.51 \pm 0.25$ & $132.2 \pm 2.7$ & $7.05 \pm 0.41$ & $74.4 \pm 4.3$ \\
\hline & 15.8 & $15.07 \pm 0.83$ & $95.5 \pm 5.3$ & $11.39 \pm 1.09$ & $72.2 \pm 6.9$ \\
\hline
\end{tabular}

Literature data suggest that removing color from red musts through treatment with PVPP also removes some laccase [31]. However, this does not appear to fully explain our results, since the recovery was quantitative when checked using spectrophotometry.

Optimization of sample preparation is anticipated to eliminate the inaccuracies due to interfering compounds in musts. The matrix effect can be overcome using the standard additions method instead of external calibration or by introducing a second filtration step through a suitable filter to eliminate small molecular weight interfering compounds (as shown above). As these two solutions imply a longer analysis time and incompatibility with in-field measurements, we will explore in future studies another alternative: optimizing the sample pretreatment by adapting the composition of the filter cartridge so that sample pretreatment will consist of a single fast filtration step. 
Compared to colorimetric kits and optical detection methods developed for laccase activity measurements, the proposed electrochemical assay has the advantages of delivering quantitative results in short time. With further improvements, as discussed above, it can be adapted for in-field measurements to provide winemakers with the needed support to take timely corrective actions and maximize the quality of their wine. Other electrochemical methods for the detection of Botrytis cinerea infection in grapes either provide another indirect evaluation of fungal infection by measuring the levels of glycerol and gluconic acid produced [25] or use an antibody that binds to several Botrytis species in addition to Botrytis cinerea. Antibody-based assays use the monoclonal antibody (BC-12.CA4) [32,33] raised against a mycelium antigen. These assays were developed in various formats, from lateral flow devices to ELISA kits and biosensors [2]. Electrochemical immunosensors developed by Fernández-Baldo et al., which used screen-printed carbon electrodes modified with carbon nanotubes [34] or magnetic beads [35] detected Botrytis antigen down to $0.008 \mu \mathrm{g} / \mathrm{mL}$ [35]. Another electrochemical biosensor reported by Binder et al. [3], based on the same antibody and a SPAuE, detected the pathogen responsible for the neck rot infection of onions. While the antibody differentiates Botrytis from potentially co-infecting Aspergillus and Penicillium microorganisms in grapes, it is not specific for Botrytis cinerea, e.g., the biosensor developed by Binder et al. responded to four Botrytis species [3]. Moreover, a standard of Botrytis cinerea antigen is not commercially available; this poses some limitations to the development of biosensors for detecting this fungal pathogen. While the above-reported electrochemical sensors for glycerol, gluconic acid and Botrytis cinerea have good analytical characteristics, laccase detection is preferable, considering the oxidative processes catalyzed by this enzyme, leading to irreversible alterations of organoleptic properties of wine, if the enzyme activity is not inhibited. To summarize, fast, simple and accurate assays for measuring laccase activity such as the electrochemical procedures proposed in this work have clear advantages and usefulness for winemakers over other existing analytical tools to check the sanitary status of the grapes and evaluate the potential for irreversible oxidative damage.

\section{Conclusions}

Collectively, the information presented above shows that the simple electrochemical assay based on commercially available SPAuEs can be used for the fast determination of laccase activity at levels relevant for the wine industry. The assay is able to differentiate between healthy grapes with low (under $1 \mathrm{U} / \mathrm{mL}$ ) laccase activities and grapes seriously affected by fungi (showing laccase levels higher than $3 \mathrm{U} / \mathrm{mL}$ ), which will pose problems for wine production. The proposed procedure for measuring laccase activity, including a fast $(<1 \mathrm{~min})$ filtration of the must through a PVPP cartridge, dilution with buffer containing ABTS and a 3-min-long electrochemical analysis with a disposable electrode, is adequate for implementation in wineries, at the point of grape processing (to determine preventive actions) or in the vineyard (to establish the spread of fungal diseases and help with taking corrective actions such as spraying with fungicides).

However, for measuring low activities of laccase, e.g., to study the mechanism of fungi attack on grapes or to sensitively measure the amounts of extracellular enzyme generated in culture media of laccase-producing fungi, analytical tools with higher sensitivity are required. The investigated approach based on CFMEs delivered better sensitivity and is amenable to further miniaturization, whereas the analysis by cyclic voltammetry offered reliability as both oxidation and reduction of ABTS were explored. An underestimation of the laccase activity with the CFMEs was observed, despite using a higher dilution factor compared to the SPAuEs; this was attributed to adsorption of must components onto the CFMEs and the presence of phenolic compounds, which consume oxidized ABTS and/or inhibit its enzymatic generation. In perspective, we plan to change the material of our microelectrodes to gold and further miniaturize the three-electrode setup to perform studies in single berries.

Differences observed between the proposed electrochemical assays with ABTS and the spectrophotometric method with syringaldazine, much higher in the case of red musts than for white musts, are attributed to the differences in the kinetics and affinity of the two substrates for laccase 
and their different susceptibility to competition with remaining phenolic compounds. Future studies will include comparison with a spectrophotometric method based on ABTS to eliminate any differences due to the different substrates and enable a clearer assessment of possible interferences in laccase determination by the proposed approach. Sample preparation will be also a focus of our future studies to address the matrix effects.

Supplementary Materials: The following are available online at http://www.mdpi.com/2227-9040/8/4/126/s1, Figure S1, Chronoamperometric signals recorded with a CFME in the presence of increasing concentrations of laccase and average calibration curve for laccase activity determination obtained with CFMEs and chronoamperometry, Figure S2: Cyclic voltammograms recorded with a SPAuE in ABTS solutions with and without laccase, Figure S3: Calibration curve for laccase activity determination using the spectrophotometric method with ABTS and comparison between the proposed electrochemical assay with ABTS and the spectrophotometric method with ABTS.

Author Contributions: Conceptualization, S.G. and E.B.; methodology, A.V.; investigation, S.G. and A.V.; resources, E.B., S.G. and A.V.; writing-original draft preparation, S.G. and A.V.; writing-review and editing, S.G, E.B. and A.V. All authors have read and agreed to the published version of the manuscript.

Funding: The authors gratefully acknowledge the financial support by the Romanian Executive Agency for Higher Education, Research, Development and Innovation (UEFISCDI), ERANET-MANUNET-III-WINBIOTOOL-2, contract 151/9.03.2020 grant.

Conflicts of Interest: The authors declare no conflict of interest.

\section{References}

1. Diguta, C.F.; Rousseaux, S.; Weidmann, S.; Bretin, N.; Vincent, B.; Guilloux-Benatier, M.; Alexandre, H. Development of a qPCR assay for specific quantification of Botrytis cinerea on grapes. FEMS Microbiol. Lett. 2010, 313, 81-87. [CrossRef] [PubMed]

2. Dewey, F.M.R. Grant-Downton, Botrytis-Biology, Detection and Quantification. In Botrytis-The Fungus, the Pathogen and its Management in Agricultural Systems; Fillinger, S., Elad, Y., Eds.; Springer International Publishing: Cham, Switzerland, 2016; pp. 17-34.

3. Binder, M. Development of a Botrytis Specific Immunosensor: Towards Using PCR Species Identification; University of Cranfield: Cranfield, UK, 2014.

4. $\quad$ Bilkiss, M.; Shiddiky, M.J.A.; Ford, R. Advanced Diagnostic Approaches for Necrotrophic Fungal Pathogens of Temperate Legumes With a Focus on Botrytis spp. Front. Microbiol. 2019, 10, 1889. [CrossRef] [PubMed]

5. Lau, H.Y.; Wang, Y.; Wee, E.J.H.; Botella, J.R.; Trau, M. Field Demonstration of a Multiplexed Point-of-Care Diagnostic Platform for Plant Pathogens. Anal. Chem. 2016, 88, 8074-8081. [CrossRef]

6. Grassin, C.; Dubourdieu, D. Quantitative determination ofBotrytis laccase in musts and wines by the syringaldazine test. J. Sci. Food Agric. 1989, 48, 369-376. [CrossRef]

7. Dubourdieu, D.; Grassin, C.; Deruche, C.; Ribéreau-Gayon, P. Mise au point d'une mesure rapide de l'activité laccase dans les moûts et dans les vins par la méthode a la syringaldazine. Application à l'appréciation de l'état sanitaire des vendanges. OENO One 1984, 18, 237-252. [CrossRef]

8. Cuadrado, M.U.; Pérez-Juan, P.M.; De Castro, M.L.; Gómez-Nieto, M.Á. A fully automated method for in real time determination of laccase activity in wines. Anal. Chim. Acta 2005, 553, 99-104. [CrossRef]

9. Detection Kit, Study of Botrytis Cinerea and Grape Juice Oxidability, Dolmar, Haro, Spain. Product information. Available online: https://www.laboratorysuppliesandreagents.com.au/test-kits/dolmar-laccase-test-kits/ (accessed on 30 October 2020).

10. Laffort Botrytest Kit Laffort, France. Product Information. Available online: https://laffort.com/wp-content/ uploads/FP/FP_EN_botrytest.pdf (accessed on 30 October 2020).

11. Australian Wine Research Institute. Development of an Alternative Method for Laccase, AWRI Annual Report 2013. pp. 23-24. Available online: https://www.awri.com.au/flip/2014-annual-report/files/assets/ basic-html/page24.html (accessed on 30 October 2020).

12. SAFEGRAPE Consortium. Final Publishable Summary Report, Biosensor Based Instrumentation to be Used in Vineyards and Wineries for Fast and Sensitive Detection of Botrytis Cinerea (Grey Rot) in Grapes (SAFEGRAPE), 2011. Available online: https://cordis.europa.eu/project/id/232453/reporting (accessed on 30 October 2020). 
13. Zouari, N.; Romette, J.-L.; Thomas, D. A continuous-flow method for the rapid determination of sanitary quality of grape must at industrial scales. J. Chem. Technol. Biotechnol. 1988, 41, 243-248. [CrossRef]

14. Zouari, N.; Romette, J.-L.; Thomas, D. Continuous-flow estimation of laccase activity in rotten grape juice by a computerized electrode. J. Chem. Technol. Biotechnol. 2007, 40, 195-201. [CrossRef]

15. MyBioSource, San Diego, USA, Laccase Assay Kit, Micromethod Catalog No: MBS779938, 2020. Available online: https://www.mybiosource.com/assay-kits/laccase/779938 (accessed on 30 October 2020).

16. BioVision Inc. Laccase Activity Assay Kit (Colorimetric), Catalog \#: K2038 2020. Available online: https://www.biovision.com/laccase-activity-assay-kit-colorimetric.html (accessed on 30 October 2020).

17. Rochelet, M.; Solanas, S.; Betelli, L.; Neuwirth, C.; Vienney, F.; Hartmann, A. Amperometric detection of extended-spectrum $\beta$-lactamase activity: Application to the characterization of resistant E. coli strains. Analyst 2015, 140, 3551-3556. [CrossRef] [PubMed]

18. Betelli, L.; Neuwirth, C.; Solanas, S.; Chantemesse, B.; Vienney, F.; Hartmann, A.; Rochelet, M. A voltammetric test for the rapid discrimination of $\beta$-lactamase-producing Enterobacteriaceae in blood cultures. Talanta 2018, 184, 210-218. [CrossRef] [PubMed]

19. Wang, J.; Timchalk, C.; Lin, Y. Carbon Nanotube-Based Electrochemical Sensor for Assay of Salivary Cholinesterase Enzyme Activity: An Exposure Biomarker of Organophosphate Pesticides and Nerve Agents. Environ. Sci. Technol. 2008, 42, 2688-2693. [CrossRef] [PubMed]

20. Shen, C.; Zhang, K.; Gao, N.; Wei, S.; Liu, G.; Chai, Y.; Yang, M. Colorimetric and electrochemical determination of the activity of protein kinase based on retarded particle growth due to binding of phosphorylated peptides to DNA-Capped silver nanoclusters. Microchim. Acta 2016, 183, 2933-2939. [CrossRef]

21. Pan, R.; Xu, M.; Jiang, D.; Burgess, J.D.; Chen, H. Nanokit for single-cell electrochemical analyses. Proc. Natl. Acad. Sci. USA 2016, 113, 11436. [CrossRef] [PubMed]

22. Sappia, L.; Felice, B.; Sanchez, M.A.; Martí, M.; Madrid, R.; Pividori, M.I. Electrochemical sensor for alkaline phosphatase as biomarker for clinical and in vitro applications. Sens. Actuators B Chem. 2019, 281, 221-228. [CrossRef]

23. Fernández-Sánchez, C.; Tzanov, T.; Gübitz, G.M.; Cavaco-Paulo, A. Voltammetric monitoring of laccase-catalysed mediated reactions. Bioelectrochemistry 2002, 58, 149-156. [CrossRef]

24. Magalhães, L.M.; Santos, M.; Segundo, M.A.; Reis, S.; Lima, J.L.F.C. Flow injection based methods for fast screening of antioxidant capacity. Talanta 2009, 77, 1559-1566. [CrossRef]

25. Cinquanta, L.; Albanese, D.; de Curtis, F.; Malvano, F.; Crescitelli, A.; di Matteo, M. Rapid Assessment of Gray Mold (Botrytis cinerea) Infection in Grapes with a Biosensor System. Am. J. Enol. Vitic. 2015, 66, 502.

26. Bourbonnais, R.; Leech, D.; Paice, M.G. Electrochemical analysis of the interactions of laccase mediators with lignin model compounds. Biochim. Biophys. Acta (BBA) Gen. Subj. 1998, 1379, 381-390. [CrossRef]

27. Klis, M.; Rogalski, J.; Bilewicz, R. Voltammetric determination of catalytic reaction parameters of laccase based on electrooxidation of hydroquinone and ABTS. Bioelectrochemistry 2007, 71, 2-7. [CrossRef]

28. Munteanu, R.-E.; Stănică, L.; Gheorghiu, M.; Gáspár, S. Measurement of the Extracellular pH of Adherently Growing Mammalian Cells with High Spatial Resolution Using a Voltammetric pH Microsensor. Anal. Chem. 2018, 90, 6899-6905. [CrossRef]

29. Hu, K.; Liu, Y.-L.; Oleinick, A.; Mirkin, M.V.; Huang, W.-H.; Amatore, C. Nanoelectrodes for intracellular measurements of reactive oxygen and nitrogen species in single living cells. Curr. Opin. Electrochem. 2020, 22, 44-50. [CrossRef]

30. Solís-Oba, M.; Ugalde-Saldívar, V.M.; González, I.; Viniegra-González, G. An electrochemical-spectrophotometrical study of the oxidized forms of the mediator 2,2'-azino-bis-(3-ethylbenzothiazoline-6-sulfonic acid) produced by immobilized laccase. J. Electroanal. Chem. 2005, 579, 59-66. [CrossRef]

31. Coulter, A. Laccase and rot: Is it there or is it not? In Australian and New Zealand Grapegrower and Winemaker; Winetitles Pty Ltd.: Broadview, Australia, 2012; pp. 69-72.

32. Dewey, F.; Yohalem, D. Detection, Quantification and Immunolocalisation of Botrytis species. In Botrytis: Biology, Pathology and Control; Elad, Y., Williamson, B., Tudzynski, P., Delen, N., Eds.; Springer Science and Business Media LLC: Dordrecht, The Netherlands, 2007; pp. 181-194.

33. Dewey, F.; Hill, M.R. Descenzo, Quantification of Botrytis and laccase in winegrapes. Am. J. Enol. Vitic. 2008, $59,47-54$. 
34. Fernández-Baldo, M.A.; Messina, G.A.; Sanz, M.I.; Raba, J. Screen-printed immunosensor modified with carbon nanotubes in a continuous-flow system for the Botrytis cinerea determination in apple tissues. Talanta 2009, 79, 681-686. [CrossRef] [PubMed]

35. Fernández-Baldo, M.A.; Messina, G.A.; Sanz, M.I.; Raba, J. Microfluidic Immunosensor with Micromagnetic Beads Coupled to Carbon-Based Screen-Printed Electrodes (SPCEs) for Determination of Botrytis cinerea in Tissue of Fruits. J. Agric. Food Chem. 2010, 58, 11201-11206. [CrossRef] [PubMed]

Publisher's Note: MDPI stays neutral with regard to jurisdictional claims in published maps and institutional affiliations.

(C) 2020 by the authors. Licensee MDPI, Basel, Switzerland. This article is an open access article distributed under the terms and conditions of the Creative Commons Attribution (CC BY) license (http://creativecommons.org/licenses/by/4.0/). 